\title{
Neurotransmitter Alterations in a Model of Perinatal Hypoxic-Ischemic Brain Injury
}

\author{
Michael V. Johnston, MD
}

\begin{abstract}
Vulnerability of neurotransmitter-specific neurons to hypoxia-ischemia was examined in the immature rat corpus striatum. Carotid artery ligation plus 2 hours of $8 \%$ oxygen atmosphere at 1 week of age produced ipsilateral striatal injury and reduced hemisphere mass 2 and 6 weeks later. Striatal injury was always more severe than damage to overlying cortex. Over half the animals had status marmoratus, a neuropathological change seen in the basal ganglia and thalamus after hypoxic-ischemic injury in full-term human infants. Two weeks after the insult, markers for cholinergic, dopaminergic, and $\gamma$-aminobutyric acid-containing neurons were all reduced, but the reduction in cholinergic markers was greater than that for the other two transmitters. Muscarinic cholinergic receptors were relatively preserved, but their distribution was disrupted. In adult animals specific activity of cholinergic neuronal markers was normal, suggesting that the balance of neurotransmitters was restored after the early insult.
\end{abstract}

Johnston MV: Neurotransmitter alterations in a model of perinatal hypoxic-ischemic brain injury. Ann Neurol 13:511-518, 1983

Perinatal hypoxic-ischemic brain injury is a major cause of motor disorders (cerebral palsy) in children and adults [9, 15]. A distinct subgroup of patients with cerebral palsy from hypoxic-ischemic insults have predominantly extrapyramidal signs, including dystonia, athetosis, and rigidity. Clinical neuropathological studies have correlated these signs with injury primarily in the basal ganglia and thalamus $[24,33\}$. A common neuropathological lesion seen in the injured basal ganglia is called status marmoratus because areas of neuronal loss are "marbled" with clumps of myelin and gliosis [22]. By analogy with other movement disorders, extrapyramidal cerebral palsy and status marmoratus might be expected to be accompanied by disruptions in basal ganglia neurotransmitter circuitry. Virtually no information about this issue is available, however [19]. Determining vulnerability patterns of functionally important basal ganglia transmitter systems is germane to understanding the pathophysiology of perinatally induced movement disorders. To examine these issues, biochemical markers for three major transmitter systems in the corpus striatum (caudateputamen) were measured in a model of hypoxicischemic injury in the immature rat.

The experiments in this report utilized rats that had undergone unilateral common carotid artery ligation plus exposure to a hypoxic environment at 7 days of age. This model, a variation of the Levine preparation [21], produces a unilateral brain injury, as described by
Rice and colleagues [30]. Neither unilateral carotid ligation nor hypoxia alone causes microscopically visible changes. Together, the two manipulations produce a spectrum of injury, varying according to the duration of hypoxia. The preparation resembles certain clinical circumstances of prolonged hypoxia and ischemia associated with high morbidity in infants $[15,23]$. The timing of the hypoxic-ischemic insult, at a brain development stage in the rat similar to that in the full-term human, also resembles that in clinical circumstances of injury. Status marmoratus occurs predominantly after insults suffered by full-term infants [22]. A preliminary report on histological and behavioral characteristics of the model was presented [16].

\section{Methods}

Pregnant Sprague-Dawley rats (Charles River) were housed in separate cages after 17 days' gestation, and pups were born on day 21 or 22 of gestation. The experiments used 369 pups from 49 litters. On the seventh day of life, pups were briefly anesthetized with ether, and either their left or right carotid arteries were ligated. Ligation of either side plus hypoxia produced similar histological lesions. Pups with right-sided ligations were used for the neurochemical studies. For each litter, sham-operated pups were prepared by manipulating the artery without ligating it. Sham-operated pups were marked with an ear punch and reared with littermates. Operations took less than 10 minutes. Pups were replaced with the dam for 2 hours before exposure to hypoxia (humidified $8 \%$ oxygen, balance nitrogen) in glass chambers warmed to $37^{\circ} \mathrm{C}$.
From the Departments of Pediatrics and Neurology, University of Michigan Medical School and Center for Human Growth and Development, 1013 Neuroscience Bldg, 1103 E Huron, Ann Arbor, MI 48109 .
Received July 19, 1982, and in revised form Sept 8 and Nov 1, 1982. Accepted for publication Nov 6, 1982.

Address reprint requests to Dr Johnston. 
In pilot experiments pups were exposed to $1,1.5,2,2.5$, or 3 hours of hypoxia plus carotid ligation. Two hours was chosen as the exposure period for the neurochemical experiments. At the conclusion of the hypoxic period, animals were removed and observed for 15 minutes before being replaced with the dam. The procedure used here was virtually identical to that reported by Rice and co-workers [30], except that ether rather than halothane/nitrous oxide was used as the anesthetic and a hypoxic interval of 2 rather than 3 hours was used.

Pups were raised to 3 weeks of age (20-25 days) or 7 weeks of age (45-56 days) before being killed for histological or neurochemical analysis. At least 10 rats at each age were prepared for histological examination by perfusion with $10 \%$ buffered formalin under deep anesthesia. Sections were stained for Nissl substance with cresyl violet, and some were stained for myelin using Weil's method [28].

For neurochemical analysis, animals were killed by cervical dislocation, and the brain was quickly removed and placed on an ice-cold $\left(4^{\circ} \mathrm{C}\right)$ glass plate. The pons-oblongata and cerebellum were separated from the forebrain. The hemispheres were then separated, and each piece was weighed on an electronic microbalance (Cahn). The corpus striatum was then carefully dissected in a standard fashion from each hemisphere to obtain the entire region free of surrounding tissue. After exposure, the striatum was scooped away from cortical white matter with curved forceps and quickly weighed. Left and right striata from hypoxic-ischemic pups as well as shamoperated hypoxic control animals were analyzed in the same assay. To reduce variation among lesions, ipsilateral striata not smaller than contralateral striata (greater than $5 \%$ weight difference) or brains with gross hemisphere cavitations were excluded.

Neurotransmitter synthetic enzymes were analyzed in aliquots of tissue homogenized by sonication in 20 volumes of ice-cold $50 \mathrm{mM}$ Tris- $\mathrm{HCl}, \mathrm{pH} 7.4$, containing $0.2 \%$ (vol/vol) Triton X-100. The homogenates were centrifuged at 12,000 $g$ at $4^{\circ} \mathrm{C}$ for 15 minutes, and portions of the supernatant were assayed. Activity of choline acetyltransferase, the acetyl. choline synthetic enzyme, was measured according to the method of Bull and Oderfeld-Nowak [3]. Activity of tyrosine hydroxylase, the rate-limiting enzyme for dopamine synthesis, was measured using the method of Coyle [5]. Activity of L-glutamate decarboxylase, the synthetic enzyme for $\gamma$-aminobutyric acid (GABA), was measured by a modification of the method of Wilson and colleagues [38], using ${ }^{14} \mathrm{C}-\mathrm{D}$, L-glutamic acid as a substrate. Protein concentration was determined using the Bio-Rad assay [2].

Synaptosomal uptake of ${ }^{3} \mathrm{H}-\mathrm{GABA},{ }^{3} \mathrm{H}$-dopamine, and ${ }^{3} \mathrm{H}$-choline was determined as markers for GABAergic, dopaminergic, and cholinergic nerve endings, respectively, as previously described [17]. Washed $P_{2}$ fractions were prepared after homogenization in $0.32 \mathrm{M}$ sucrose $\left(4^{\circ} \mathrm{C}\right)$. Uptake of ${ }^{3} \mathrm{H}-\mathrm{GABA}(34.7 \mathrm{Ci} / \mathrm{mM}$, New England Nuclear) was performed using striatal homogenates from the equivalent of 2 mg of tisssue at a substrate concentration of $10^{-6} \mathrm{M}$ in $1 \mathrm{ml}$ of Kreb's Ringer phosphate buffer. Incubation time was 2 minutes at $37^{\circ} \mathrm{C}$. To terminate incubation, $2 \mathrm{ml}$ of ice-cold Kreb's buffer without sodium (no- $\mathrm{Na}^{+}$) was added, and the tubes were contrifuged at $19,000 \mathrm{~g}$ for 15 minutes at $4^{\circ} \mathrm{C}$. The supernatant was discarded, and the pellets were washed superficially twice in no- $\mathrm{Na}^{+}$buffer, dissolved in Protosol (New England Nuclear), and counted by liquid scintillation spectrometry. Blank values were determined in the presence of no- $\mathrm{Na}^{+}$buffer.

${ }^{3} \mathrm{H}$-dopamine uptake was determined using a similar procedure with a substrate concentration of $5 \times 10^{-8} \mathrm{M}(20 \mathrm{Ci} /$ mmol, New England Nuclear) and a washed $\mathrm{P}_{2}$ fraction from $2 \mathrm{mg}$ of tissue. Incubation time was 4 minutes. Blank values were determined in the presence of $10^{-6} \mathrm{M}$ benztropine [7]. ${ }^{3} \mathrm{H}$-choline uptake was determined using a substrate concentration of $5 \times 10^{-8} \mathrm{M}\left({ }^{3} \mathrm{H}\right.$-choline $\mathrm{Cl}, 80 \mathrm{Cl} / \mathrm{mmol}$, New England Nuclear) with $5 \mathrm{mg}$ of tissue and 4 minutes' incubation. Blank values were calculated from tubes in which 0.32 $M$ sucrose was substituted for sodium chloride in the buffer. Endogenous dopamine in the striata of 7-weekold rats was measured using high-performance liquid chromatography with electrochemical detection [1].

Muscarinic receptor binding was measured in homogenates of 3-and 7-week-old striata using the method of Wastek and Yamamura [36]. Tissue was homogenized by sonication in 200 volumes of $50 \mathrm{mM}$ Tris- $\mathrm{HCl}, \mathrm{pH} \mathrm{7.7,} \mathrm{and} \mathrm{the}$ membranes were washed once by centrifugation at $48,000 \mathrm{~g}$. Homogenates containing $1 \mathrm{mg}$ of tissue were incubated together with a saturating concentration $(1.4 \mathrm{nM})$ of ${ }^{3} \mathrm{H}$ quinuclidinyl benzilate $(\mathrm{QNB}, 33 \mathrm{Ci} / \mathrm{mmol}$, New England Nuclear) in a total volume of $4 \mathrm{ml}$ at $37^{\circ} \mathrm{C}$ for 1 hour. Bound radioactivity was separated from free by filtration through glass fiber filters and was counted by liquid scintillation spectrometry.

The distribution and density of receptors in 3-week-old animals were examined by in vitro quantitative autoradiography for ${ }^{3} \mathrm{H}-\mathrm{QNB}$ on frozen sections [26]. Sections of $30 \mu$ were cut from fresh frozen brains on a Harris cryostat at $-20^{\circ} \mathrm{C}$ and mounted on subbed slides. The mounted tissue was given three successive 5-minute washes with Dulbecco's phosphate-buffered saline and immersed in $200 \mathrm{ml}$ of buffer containing $1.4 \mathrm{nM}^{3} \mathrm{H}-\mathrm{QNB}$ at $20^{\circ} \mathrm{C}$ for 2 hours. After incubation, the slides were washed in two sequential 5 -minute buffer washes, and tissue was blown dry with a cool stream of air. The slides were then apposed to a sheet of tritiumsensitive film (Ultrofilm- ${ }^{3} \mathrm{H}, \mathrm{LKB}$ ) along with ${ }^{1 / 4} \mathrm{C}$ standards (Amersham) in an $\mathrm{x}$-ray cassette for 12 days. After the film was developed, binding was quantitated by comparing the film density in various regions with the standards using a computerized microdensitometer [26]. After a satisfactory film image was obtained, the tissue sections were stained for Nissl substance to identify anatomical landmarks and correlate them with the autoradiogram.

\section{Results}

\section{Characteristics of the Hypoxic-Ischemic Injury}

Carotid ligation plus hypoxia for 2 hours at 1 week of age produced a smaller hemisphere ipsilateral to the ligation at 3 or 7 weeks of age (Fig 1). As previously reported for acute histological effects in the same model [30], carotid ligation alone or hypoxia alone produced no gross or light microscopic effects. Pilot experiments established that the late morphological effects were related to the duration of hypoxia. One hour of $8 \%$ oxygen plus ligation produced no appreciable 


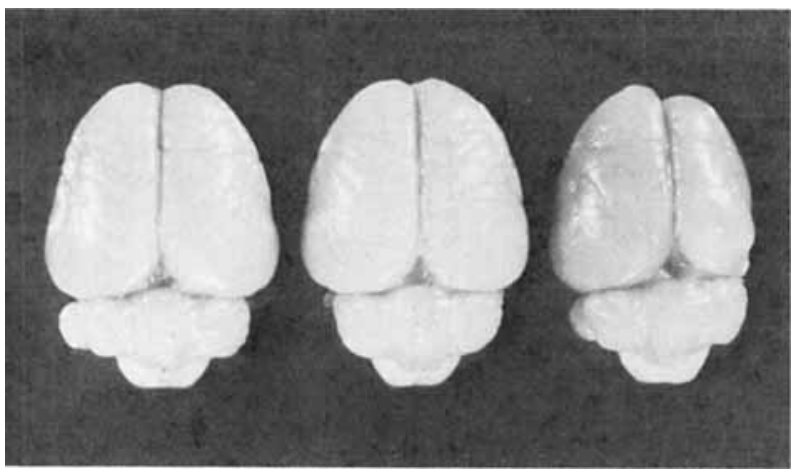

Fig 1. Gross appearance of unilateral bypoxic-ischemic injured rat brains 2 weeks after bypoxia plus carotid ligation at 1 week of age. Brain in center is control far comparison; brain on the right bad a right common carotid ligation; brain on the left is from an animal with a left carotid ligation. Note bemisphere asymmetry without gross cavitation. Range of asymmetry indicates the range of lesions studied in neurocbemical experiments.

change in hemisphere size or appearance, but 1.5 or 2 hours of hypoxia after carotid ligation produced obvious hemisphere asymmetry in three-quarters of the animals, with little difference between the two intervals. Although smaller than the other side, the ipsilateral hemisphere subjected to 2 hours of hypoxia-ischemia was usually smooth or mildly scarred. Following 2.5 or 3 hours of hypoxia plus ligation, however, gross cavitations and cortical destruction were common. Cell loss and reduction in the mass of the corpus striatum were more severe than damage to overlying cortex at 1.5, 2, or 2.5 hours of hypoxia. Accordingly, 2 hours of hypoxia was chosen for these experiments, because it produced disproportionate injury in the striatum.
Of 319 rat pups from 41 litters, $63 \%$ survived ligation plus 2 hours of $8 \%$ oxygen environment, but $93 \%$ of sham-operated rats survived the same hypoxic period. Of the hypoxic-ischemic survivors, $80 \%$ turned or twisted toward the side of the ligation for approximately 10 minutes after being removed from the chamber [16]. After a short recovery period, during which they remained inactive and lethargic, they appeared normal in their casual behavior. About $10 \%$ of the survivors were runted, but the rest grew and gained weight normally.

Of the rats dissected for neurochemical analysis, $85 \%$ had noticeable hemisphere asymmetry and more than $5 \%$ reduction in ipsilateral striatal wet weight. In these animals, at 3 weeks of age the mean ipsilateral hemisphere weight was reduced by $18 \%$, and striatal weight was $37 \%$ lower compared with the other side (Table). Similar changes were found in the group of adult animals. The distribution of weight changes in the lesioned striata used for neurochemical analysis is shown in Figure 2. It is noteworthy that the contralateral hemisphere and striatum as well as the ponsoblongata and cerebellum were not significantly reduced by the insult (see the Table).

\section{Histological Changes}

The hypoxic-ischemic injury produced considerable shrinkage and cell loss in the ipsilateral striatum in both 3-week-old and adult animals. The ipsilateral globus pallidus was also smaller. In the adult animals, more than half had status marmoratus changes with gliosis and abnormal clumps of myelin (Fig 3). The other animals had definite perikaryal loss with an increase in the density of remaining myelinated fascicles. Damage was

Regional Brain Weight following Hypoxic-Ischemic Injury 7 Days after Birth

\begin{tabular}{|c|c|c|c|c|c|c|}
\hline & \multicolumn{3}{|c|}{ Sham + Hypoxia } & \multicolumn{3}{|c|}{ Unilateral CCL + Hypoxia } \\
\hline & Ipsilateral & Contralateral & Change $(\%)$ & Ipsilateral & Contralateral & Change $(\%)$ \\
\hline \multicolumn{7}{|l|}{ 3-WEEK-OLD PUPS } \\
\hline Hemisphere & $504 \pm 9$ & $502 \pm 16(n=15)$ & 0 & $433 \pm 25^{a}$ & $530 \pm 8(\mathrm{n}=15)$ & -18 \\
\hline Corpus striatum & $27.4 \pm 1$ & $27.3 \pm 1 \quad(n=26)$ & 0 & $15.0 \pm 1^{\mathrm{a}}$ & $23.7 \pm 1(\mathrm{n}=47)$ & -37 \\
\hline $\begin{array}{l}\text { Hindbrain } \\
\text { (pons-oblongata, } \\
\text { cerebellum) }\end{array}$ & \multicolumn{3}{|c|}{$298 \pm 7$} & \multicolumn{3}{|c|}{$284 \pm 7$} \\
\hline \multicolumn{7}{|l|}{ 7-WEEK-OLD PUPS } \\
\hline Hemisphere & $642 \pm 15$ & $638 \pm 16(\mathrm{n}=15)$ & +1 & $531 \pm 13^{a}$ & $633 \pm 12(\mathrm{n}=15)$ & -16 \\
\hline Corpus striatum & $39 \pm 1$ & $39 \pm 1 \quad(n=20)$ & 0 & $24 \pm 1^{a}$ & $37 \pm 1 \quad(\mathrm{n}=34)$ & -35 \\
\hline $\begin{array}{l}\text { Hindbrain } \\
\text { (pons-oblongata, } \\
\text { cerebellum) }\end{array}$ & \multicolumn{3}{|c|}{$418 \pm 15$} & \multicolumn{2}{|c|}{$420 \pm 32$} & \\
\hline
\end{tabular}

${ }^{a} p<0.001$, ipsilateral vs contralateral, using Student's $t$ test for paired values.

All values are expressed in milligrams and as mean \pm standard error of the mean. The brains were divided and dissected as described in Methods. $\mathrm{CCL}=$ common carotid artery ligation. 


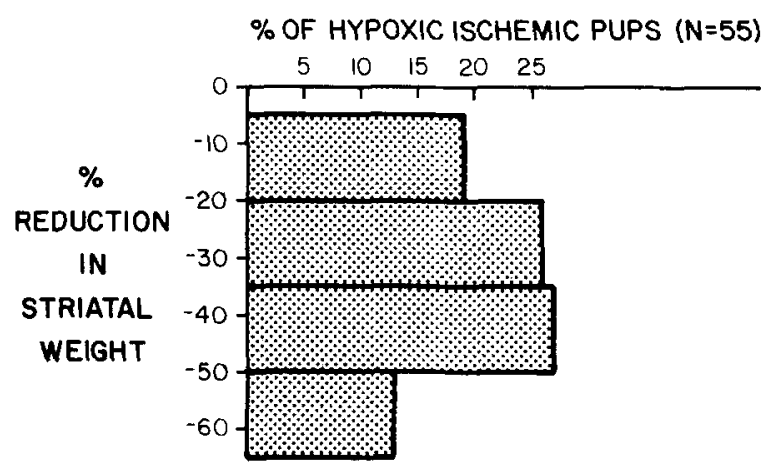

Fig 2. Distribution of weight reductions in bypoxic-ischemic injured striata (compared with striatal weight of opposite side) in a series of 55 rats. Fifteen percent of the group bad less than a $5 \%$ difference and were not included.

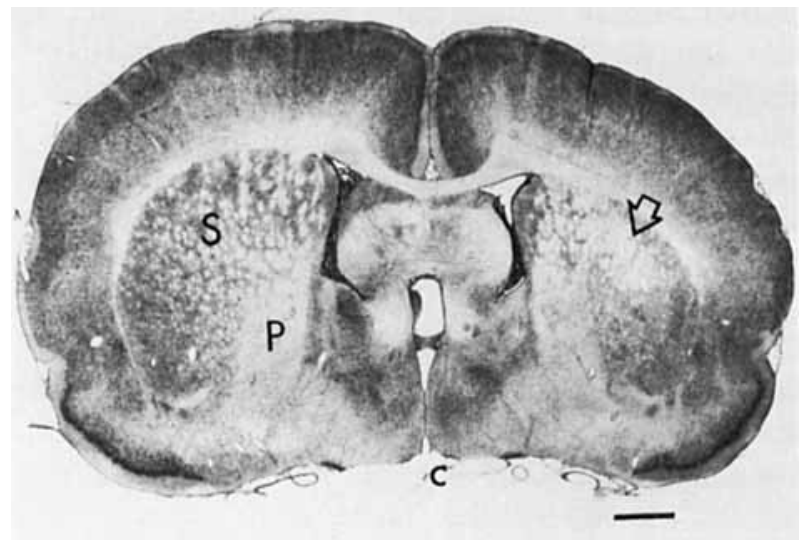

Fig 3. Photograph of a coronal Nissl-stained section of a bypoxicischemic lesioned rat brain. Animal was 6 weeks old when killed, and the insult was incurred 5 weeks before. Arrow points to an area of clumped myelin within a sbrunken striatum with considerable cell loss (status marmoratus). The size of the globus pallidus is also reduced. Altbough the cortical expanse is reduced. there are no areas of necrosis or cavitations. ( $\mathrm{S}=$ corpus striatum; $\mathrm{P}=$ globus pallidus; $\mathrm{c}=$ optic chiasm. Bar $=1 \mathrm{~mm}$.)

always more severe in the most dorsal segment of the striatum. Three-week-old pups had similar microscopic changes with respect to cellular loss and location of damage. Hypermyelination was not yet present, however, probably because of the relative immaturity of this brain component. In comparison to the striatal changes, microscopic alterations in the cortex were more subtle. Although the cortical expanse was obviously reduced, definite necrotic areas or architectonic disruptions were frequently absent (see Fig 3). When present, areas of cortical necrosis were located in the posterior lateral cortex in the region served by the middle cerebral artery.

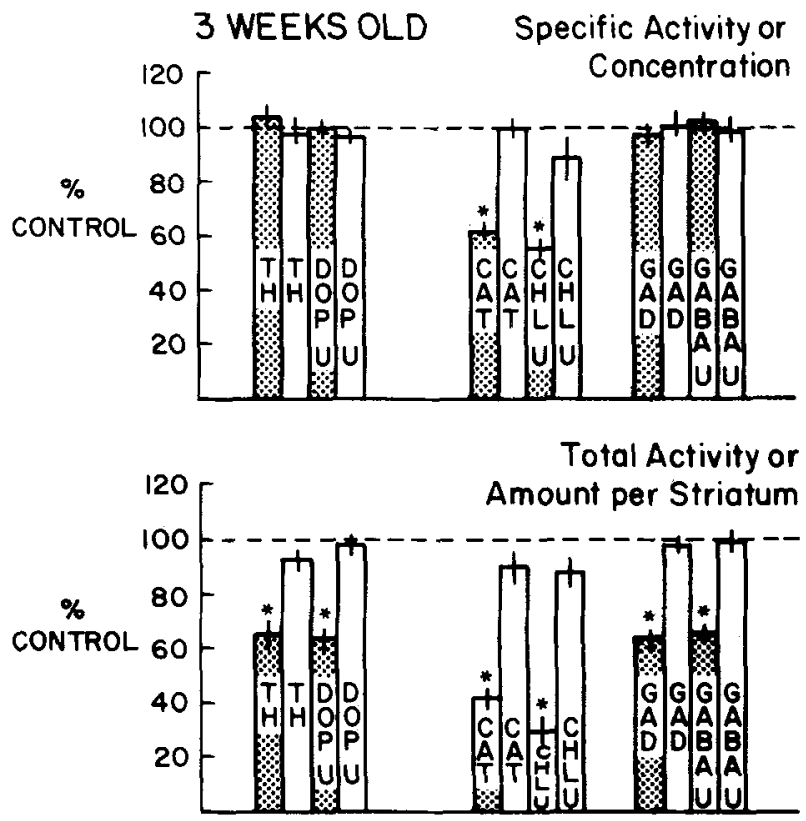

Fig 4. Levels of neurotransmitter markers in bypoxic-ischemic lesioned striata of 3-week-old rats (stippled bars) versus the contralateral levels (open bars), compared with mean levels in shamoperated bypoxic controls (dashed horizontal lines). Bar beight indicates mean \pm standard error of the mean, $n=10-16$ in each group from two or three separate experiments. Asterisk indicates $\mathrm{p}<0.01$ using t test for paired values. Total activity was calculated by multiplying the striatal weight by the specific activity or concentration of the marker. ( $\mathrm{TH}=$ tyrosine bydroxylase; DOP U $={ }^{3} \mathrm{H}$-dopamine uptake; CA'T = cboline acetyltransferase; $\mathrm{CHL} \mathrm{U}={ }^{3} H$-choline uptake; $\mathrm{GAD}=L$-glutamate decarboxylase; GABA $U={ }^{3} H-G A B A$ uptake.) Mean control specific activities or concentrations: $T H=240 \mathrm{pmol} \cdot \mathrm{mg}$ tissue $\mathrm{e}^{-1} \cdot \mathrm{br}^{-1} ; D O P U=1.5 \mathrm{pmol} \cdot \mathrm{mg}^{-1} \cdot 4 \mathrm{~min}^{-1} ; C A T$ $=12 \mathrm{nmol} \cdot \mathrm{mg}^{-1} \cdot \mathrm{br}^{-1}:$ CHL $U=0.043 \mathrm{pmol} \cdot \mathrm{mg}^{-1} \cdot 4$ $\mathrm{min}^{-1} ; G A D=5.2 \mathrm{nmol} \cdot \mathrm{mg}^{-1} \cdot \mathrm{br}^{-1} ; G A B A U=60$ pmol $\cdot \mathrm{mg}^{-1} \cdot 2 \mathrm{~min}^{-1}$. There was no difference between the two sides in protein concentration.

Neurotransmitter Markers at 2 and 6 Weeks after Injury The lesioned striata were analyzed for biochemical markers for dopaminergic, acetylcholinergic, and GABAergic neurons. In each case at least two independent markers for each neuronal type were used to attempt assessment of changes in populations of nerve terminals. The striatum contralateral to carotid ligation served as an internal hypoxic control for the ipsilateral hypoxic-ischemic injured side. To control for possible subtle effects of the carotid ligation on the opposite side, sham-operated hypoxic controls were included in each assay. Pilot experiments did not identify significant effects of hypoxia alone on the measurements.

Two weeks after the injury the biochemical results indicated that ipsilateral to the carotid ligation the cholinergic neuronal markers, choline acetyltransferase and ${ }^{3} \mathrm{H}$-choline uptake, were reduced to $62 \%$ and 


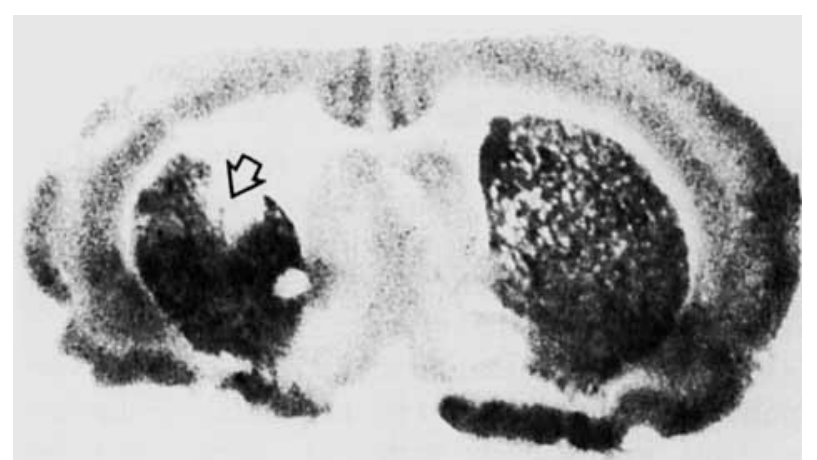

A

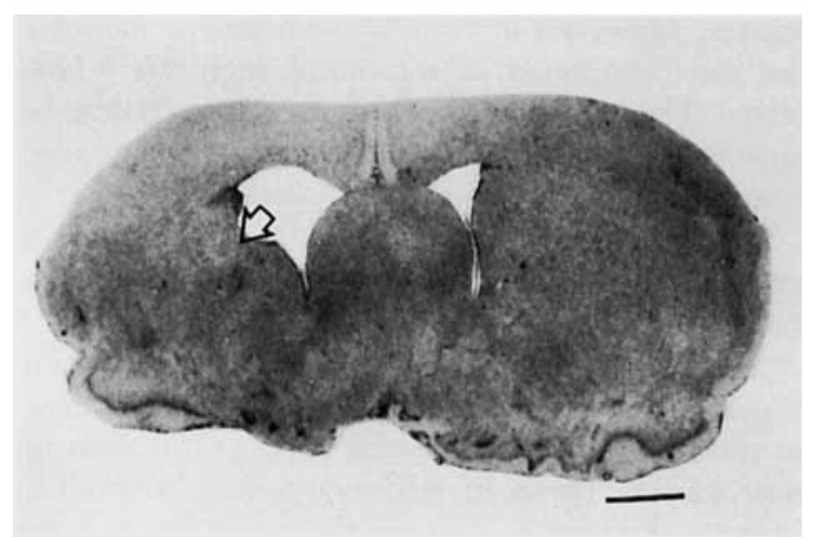

B

Fig 5. Autoradiogram showing distribution and density of muscarinic receptors in a 3-week-old rat with a unilateral bypoxicischemic injury at 1 week of age. (A) shows the image produced by incubation of the tissue slice in vitro with ${ }^{3} H-Q N B$, as described in Methods. Arrow indicates an area without receptors, surrounded by a smaller corpus striatum with areas of confluent increased receptor density (increased blackness). (B) shows the lightly Nissl stained section used for the autoradiogram in (A) after the image was developed. The arrow, at the same location as the arrow in (A), indicates an area of intense gliosis and scarring. $($ Bar $=1 \mathrm{~mm}$.)

$55 \%$, respectively, of control values (Fig 4). In contrast, tyrosine hydroxylase activity and ${ }^{3} \mathrm{H}$-dopamine synaptosomal uptake, markers for dopaminergic nerve endings, were present at the same levels on both sides. Similarly, the GABAergic markers, L-glutamate decarboxylase and ${ }^{3} \mathrm{H}-\mathrm{GABA}$ uptake, remained at control levels. Considered in terms of total markers per striatum, all three groups were reduced ipsilateral to the carotid ligation, with the cholinergic markers showing the largest decreases (see Fig 4).

Because presynaptic cholinergic markers were most heavily injured by the insult, it was of interest to assess the distribution of corresponding postsynaptic receptors. This was done using in vitro receptor autoradiography for ${ }^{3} \mathrm{H}-\mathrm{QNB}$, a potent muscarinic receptor antagonist. Autoradiography at 3 weeks of age demonstrated that muscarinic receptors were relatively preserved in the injured striatum, except in the relatively small regions of intense gliosis and necrosis at its

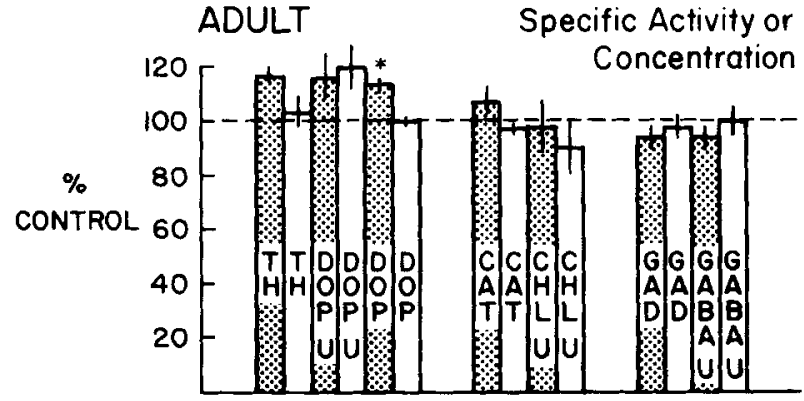

Total Activity or

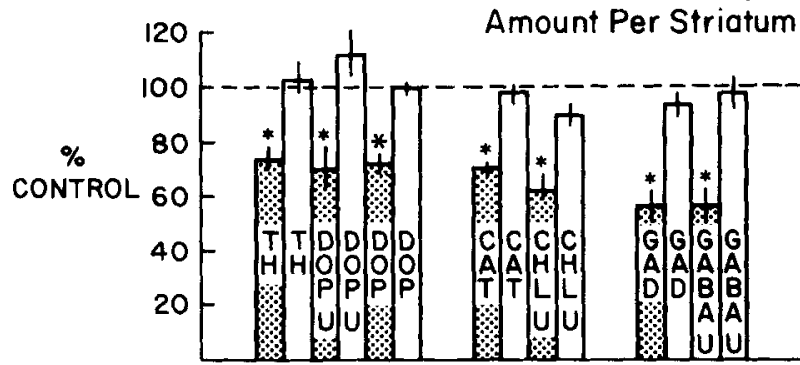

Fig 6. Levels of neurotransmitter markers in bypoxic-iscbemic lesioned striata from 7-week-old rats (stippled bars) versus the contralateral levels (open bars), compared with mean levels in sham-operated bypoxic controls (dashed horizontal lines). Bar beight indicates mean \pm standard error of the mean, $n=$ 6-10 in each group from two or three separate experiments. Total activity calculated as for Figure 4. Asterisk indicates $\mathrm{p}<0.01$. (DOP = endogenous dopamine; other abbreviations as in Figure 4.) Mean control values: $\mathrm{TH}=380 \mathrm{pmol} \cdot \mathrm{mg}$ tissue $^{-1} \cdot \mathrm{hr}^{-1}$;

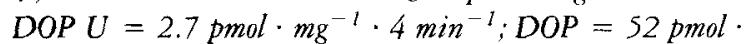
$\mathrm{mg}^{-1} ; C A T=20 \mathrm{nmol} \cdot \mathrm{mg}^{-1} \cdot \mathrm{hr}^{-1} ; \mathrm{CHLU}=0.11 \mathrm{pmol} \cdot$ $\mathrm{mg}^{-1} \cdot 4 \mathrm{~min}^{-1} ; G A D=12 \mathrm{nmol} \cdot \mathrm{mg}^{-1} \cdot \mathrm{br}^{-1} ; G A B A U$ $=25 \mathrm{pmol} \cdot \mathrm{mg}^{-1} \cdot 4 \mathrm{~min}^{-1}$.

dorsal border (Fig 5). In some regions, the concentration of receptors was increased compared with the other side, and the normal mosaic pattern was distorted into a dense, confluent mass. Assay of ${ }^{3} \mathrm{H}-\mathrm{QNB}$ receptors in striatal homogenates also indicated that muscarinic receptors were relatively preserved. Each side at 3 weeks contained $45 \pm 4 \mathrm{fmol} / \mathrm{mg}$ tissue (mean \pm standard error of the mean; $n=6$ ), apparently reflecting the average of areas with few receptors and others with preserved or supranormal densities.

Although the concentrations of cholinergic markers were disproportionately reduced in the injured striatum at 3 weeks, the reduction was no longer present in the adult animals (Fig 6). Because the histological analysis and striatal wet weight (see the Table) indicated that the older animals were injured as severely as QNB receptors were present in similar concentrations on the two sides in the older animals [mean \pm standard error of the mean, $180 \pm 10 \mathrm{fmol} / \mathrm{mg}$ ipsilateral versus $160 \pm 10$ contralateral $(\mathbf{n}=5)$, not significant $\}$. 
Levels of markers for dopaminergic terminals were slightly higher than control levels, with endogenous dopamine being modestly but significantly higher (see Fig 6). In the older animals, calculation of total markers per striatum indicated that ipsilateral dopamine markers were present at $75 \%$, cholinergic markers at $70 \%$, and GABAergic markers at $58 \%$ of control levels.

\section{Discussion}

An animal model is necessary to gain insight into patterns of hypoxic-ischemic damage and reorganization in the developing brain, because human cases are difficult to study and are often heterogeneous. When initiated at 1 week of age in the rat, the experimental hypoxic-ischemic conditions can be manipulated so that the corpus striatum is preferentially damaged. The model reproduces status marmoratus, a distinct agerelated phenomenon in human neuropathology, often seen after perinatal insults. In spite of moderate variation among lesioned animals, reasonably homogeneous groups can be chosen by observing the degree of hemisphere asymmetry and cortical scarring. Although the lesioned animals do not develop obvious movement disorders, their absence could be related to the unilateral nature of the insult or to lack of sensitive observational techniques. The animals do manifest transient acute turning behavior and persistent asymmetrical drug-induced turning [16] similar to that produced by other striatal lesions in adult animals [8].

The rat corpus striatum is a satisfactory region for examining differences in vulnerability of neurotransmitter-specific neurons to hypoxia-ischemia. Its blood supply is relatively homogeneous throughout, and the transmitter systems are also distributed relatively evenly. In immature rodents, dopaminergic terminals projected from the substantia nigra are organized in islands with a diffuse distribution [35]. Cholinergic innervation is localized in large interneurons with perikarya widely distributed in the striatum $\{20\}$. GABAergic neurons are small and medium sized. Some are interneurons, and others project to the substantia nigra and globus pallidus [29]. Therefore, each of the three systems is likely to be exposed to similar hypoxic-ischemic conditions. Changes in the neurotransmitter-specific markers for these systems probably reflect the relative vulnerability of each neuronal type to the insult.

\section{Relative Vulnerability of Striatal Neurons}

In this experimental model hypoxia-ischemia produced a long-term reduction in striatal mass, as well as in total biochemical markers for dopaminergic, cholinergic, and GABAergic nerve terminals. Agreement between results of assays for at least two markers for each neuronal type suggests that the reduction reflects loss of neurons or nerve terminals, or both, rather than temporary disruption of intracellular neurotransmitter metabolism. Two weeks after the insult, at a time when much necrotic debris has been removed, cholinergic markers were reduced more than markers for the other two systems. The data indicate that all three neuronal types are vulnerable to the perinatal hypoxic-ischemic injury, although cholinergic neurons are somewhat more sensitive than the others.

In comparison to the reduced concentration of presynaptic cholinergic markers, muscarinic cholinergic receptors are relatively preserved in the dystrophic striatum outside of small areas of intense gliosis and damage. However, in vitro autoradiography indicates that the distribution of muscarinic receptors is disrupted. These receptors are normally organized in islands in a mosaic pattern which resembles that of opiate receptors and acetylcholinesterase activity [14].

The acute effects of hypoxia and ischemia on metabolism of neurotransmitter systems have been studied by several investigators [12], but few studies have examined long-term effects [32]. At least with respect to effects on dopamine systems, the immature rat model does duplicate some acute effects seen in older animals. The acute ipsilateral turning behavior is similar to that seen in adult rats and gerbils, and in both the immature rat and older animals, the turning is associated with a large ipsilateral fall in endogenous dopamine $[16,39]$. However, the relative vulnerability of neurotransmitter systems in the infant rat appears to differ from that seen in adult animals. Francis and Pulsinelli $[11]$ reported evidence that GABAergic striatal neurons may be more vulnerable to ischemia than cholinergic neurons in adult rats. Studies from adult gerbils and rats indicate that dopaminergic nerve terminals are more vulnerable to ischemia than GABAergic neurons [25, 37].

In immature animals, ontogeneric differences among distinct transmitter systems at the time of injury might be expected to have an important modifying influence. In 1-week-old rats, dopamine terminal biochemical development is the most advanced of the three systems studied [7]; cholinergic neurons are the least mature $[6,18]$. Cholinergic neurons may be more severely damaged in the immature rat striatum because they are undergoing vigorous, rapid differentiation at the time of injury. Heightened energy requirements for actively differentiating neurons may be partially responsible for this vulnerability [10]. Alternately, the vulnerability could be related to some other special feature of immature cholinergic neurons. In adults, acetylcholine turnover is very sensitive to hypoxia. [12].

\section{Age-related Plasticity in the Injured Striatum}

Morphological and biochemical modifications occur in the injured striatum between the weanling period and adulthood. Myelinating fiber bundles which are rela- 
tively indistinct at 3 weeks of age become clearly defined in adulthood. Foci of necrosis seen at 3 weeks become occupied with myelin clumps at later times. Biochemically, the reduction in concentrations of cholinergic markers seen at 3 weeks is no longer detected at 7 weeks. In contrast to the situation in the immature rat, assessment of neuronal populations based on total neuronal markers in adult animals indicates that GABAergic neurons rather than cholinergic ones are the most depleted group. Also, the concentration of dopamine is modestly elevated on the injured side of adult but not immature animals. Because morphological features of injury were similar at 3 and 7 weeks, the biochemical results suggest that the balance of neurotransmitters was readjusted during later maturation. This readjustment could occur through regeneration of cholinergic nerve terminals or by progressive loss of $\mathrm{GABAergic}$ or other nerve terminals.

\section{Possible Relevance to Human Pathophysiology}

Imbalances among different striatal neurotransmitter systems have been linked to several movement disorders [34], but a similar hypothesis has not emerged for motor disorders associated with hypoxic-ischemic damage. Formation of disordered neuronal pathways in response to early injury is well documented in several mammalian systems, however $[13,27]$. The animal model affords an opportunity to explore factors determining brain reorganization after an insult similar to that sustained by human infants. It is noteworthy that significant histopathological and neurochemical changes occur with age in the rat just as pathological and neurological signs evolve over time in infants [19, 22].

No single drug has been dramatically successful in treating movement disorders related to human cases of status marmoratus, but a muscarinic cholinergic antagonist [4] is sometimes effective in instances of dystonia related to perinatal insults, and success with L-dopa in cases of choreoathetosis has also been reported in a few patients [31]. Both drugs may act to diminish cholinergic neurotransmission, one by blocking muscarinic effects of acetylcholine on other striatal neurons and the other by a dopaminergic inhibitory effect on striatal cholinergic neurons. In the rat model, cholinergic neuronal markers were more heavily injured than dopaminergic or GABAergic neuronal markers. Muscarinic receptor recognition sites were relatively preserved but their organization was disrupted. In older animals, the cholinergic balance was restored. Both the animal observations and clinical pharmacological reports suggest that cholinergic synaptic abnormalities may play a role in the pathophysiology of this injury. The animal model also suggests, however, that damage to a variety of other systems contributes to the final patterns of disordered neuronal circuitry.
Supported in part by Grant NS R017542 from the National Institutes of Health and grants from the Michigan Memorial Phoenix Foundation and the United Cerebral Palsy Research and Education Foundation.

The author is the recipient of Teacher-Investigator Award NS 00603 from the National Institute of Neurological and Communicative Disorders and Stroke.

Michele Eickholt provided excellent rechnical assistance, and Nancy Peterson prepared the manuscript. Drs Robert Vannucci, John Penney, and Anne Young also provided helpful assistance and advice.

\section{References}

1. Anderson GM, Young JG, Shaywitz BA, Batter DK, Cohen DJ: Simplified liquid chromatographic-electrochemical determination of norepinephrine and dopamine in rat brain. J Chromatogr 181:453-455, 1980

2. Bradford $\mathrm{M}$ : A rapid, sensitive method for the quantification of microgram quantities of protein utilizing the principle of protein dye binding. Anal Biochem 72:248-253, 1976

3. Bull G, Oderfeld-Nowak B: Standardization of a radiochemical assay of choline acetyltransferase. J Neurochem 18:935-947, 1971

4. Burke RE, Fahn S: Double-blind evaluation of high-dose trihexyphenidyl treatment of torsion dystonia (abstract). Neurology 32:A112, 1982

5. Coyle JT: Tyrosine hydroxylase in rat brain, cofactor requirements, regional and subcellular distribution. Biochem Pharmacol 21:1935-1944, 1972

6. Coyle JT: Biochemical aspects of neurotransmission in the developing brain. Int Rev Neurobiol 20:65-102, 1977

7. Coyle JT, Campochiaro P: Ontogenesis of dopamine-cholinergic interactions in the rat striatum: a neurochemical study. J Neurochem 27:673-678, 1976

8. Coyle JT, Schwarcz R: Lesion of striatal neurones with kainic acid provides a model for Huntington's chorea. Nature 263:244-246, 1976

9. Crothers BS, Paine RS: The Natural History of Cerebral Palsy. Cambridge, Harvard University Press, 1959

10. DiRocco RJ, Hall WG: Metabolic neural mapping in neonatal rats. J Neurosci Res 6:13-19, 1981

11. Francis AJ, Pulsinelli W: Selective ischemic damage to striatal GABAergic neurons. Abstr Soc Neurosci 6:599, 1980

12. Gibson GE, Pulsinelli W, Blass JL, Duffey TE: Brain dysfunction in mild to moderate hypoxia. Am J Med 70:1247-1254, 1980

13. Goldman-Rakic PS: Development and plasticity of primate frontal association cortex. In Schmitt FO, Worden FG, Dennis SD (eds): The Cerebral Cortex. Cambridge, MA, MIT, 1981, pp 69-97

14. Herkenham M, Pert CB: Mosaic distribution of opiate receptors, parafascicular projections and acetylcholinesterase in rat striatum. Nature 291:415-417, 1981

15. Hill A, Volpe JJ: Seizures, hypoxic-ischemic brain injury, and intraventricular hemorrhage in the newborn. Ann Neurol 10:109-121, 1981

16. Johnston MV: Perinatal hypoxic-ischemic injury of rat brain: morphological, neurochemical and behavioral correlates (abstract). Ann Neurol 10:293, 1981

17. Johnston MV, Coyle JT: Histological and neurochemical effects of fetal treatment with methylazoxymethanol on rat neocortex in adulthood. Brain Res 170:135-155, 1979

18. Johnston MV, Coyle JT: Development of central neurotransmitter systems. In Elliott K, Whelan J (eds): The Fetus and Independent Life. Ciba Symposium 86. London, Pitman, 1981, pp 251270 
19. Johnston MV, Singer HS: Brain neurotransmitters, neuromodulators and pediatrics. Pediatrics 70:57-67, 1982

20. Kimura H, McGeer P, Peng JH, McGeer EG: The central cholinergic system studied by choline acetyltransferase immunohistochemistry in the cat. J Comp Neurol 200:151-201, 1981

21. Levine S: Anoxic-ischemic encephalopathy in rats. Am J Pathol $36: 1-17,1960$

22. Malamud N: Status marmoratus: a form of cerebral palsy following either bith injury or inflammation of the central nervous system. J Pediatr 37:610-619, 1950

23. Myers RE: Experimental models of perinatal brain damage: relevance to human pathology. In Gluck L (ed): Intrauterine Asphyxia and the Developing Brain. Chicago, Year Book, 1977, pp 37-97

24. Norman RM: Malformations of the nervous system, birth injury and diseases in early life. In Blackwood W, McMenemy WH, Meyer A, et al (eds): Greenfield's Neuropathology. Baltimore, Williams \& Wilkins, 1967, pp 324-440

25. Pastusyko A, Wilson DF, Erecinska M: Neurotransmitter metabolism in rat brain synaptosomes: effects of anoxia and $\mathrm{pH}$. J Neurochem 38:1657-1667, 1982

26. Penney JB, Pan HS, Young AB, Frey KA, Dauth GW: Quantitative autoradiography of ${ }^{3} \mathrm{H}$-muscimol binding in rat brain. Science 214:1036-1038, 1981

27. Rakic P: Development of visual centers in the primate brain depends on binocular competition before birth. Science 214:928-931, 1981

28. Ralis HM, Beesley RA, Ralis ZA: Techniques in Neurohistology. London, Butterworths, 1971

29. Ribak CE, Vaughn K, Barber K, et al: Immunocytochemical localization of glutamate decarboxylase in rat substantia nigra. Brain Res 1 16:287-293, 1976
30. Rice JE III, Vannucci RC, Brietley JB: The influence of immaturity on hypoxic-ischemic brain damage in the rat. Ann Neurol 9:131-141, 1981

31. Rosenthal RK, McDowell FH, Cooper W: Levodopa therapy in athetoid cerebral palsy. Neurology (Minneap) 22:1-11, 1972

32. Shellenberger MK: Persisting effects on adult brain monoamines of neonatal distress and carbon monoxide exposure. Neuroscience 7:667-671, 1982

33. Spiegel EA, Baird HW: Athetotic syndromes. In Vinken PJ, Bruyn BW (eds): Diseases of the Basal Ganglia. Handbook of Neurology, Vol 6. Amsterdam, North Holland, 1968, pp 440475

34. Spokes EG: The neurochemistry of Huntington's chorea. Trends Neurosci 4:115-118, 1981

35. Tennyson VM, Barrett RE, Cohen G, Cote L, Heikkila R, Mytilimeou $C$ : The development of the neostriatum of the rabbit: correlation of fluorescence histochemistry, electron microscopy, endogenous dopamine levels and ${ }^{3} \mathrm{H}$-dopamine uptake. Brain Res 46:251-285, 1972

36. Wastek GJ, Yamamura $\mathrm{HI}$ : Biochemical characterization of the muscarinic cholinergic receptor in human brain: alterations in Huntington's disease. Mol Pharmacol 14:768-780, 1978

37. Weinberger J, Cohen $G$ : The differential effect of ischemia on the active uptake of dopamine, and $\gamma$-aminobutyric acid and glutamate by brain synaptosomes. J Neurochem 38:963-968, 1982

38. Wilson SH, Schrier BK, Farber JL, Thompson EJ, Rosenberg RN, Blume AJ, Nirenberg MW: Markers for gene expression in cultured cells from the nervous system. J Biol Chem 247:31593169, 1972

39. Zervas NT, Hori H, Negora M, Wurtman RJ, Larin F, Lavyne NT: Reduction in brain dopamine following experimental cerebral ischemia. Nature 247:283-284, 1974 